\title{
Determinação da Solubilidade Protéica de Farinhas de Subproduto de Aves com a Pepsina em Baixa Concentração
}

\author{
Claudio Bellaver1, 2, Dirceu Luís Zanotto', Antônio Lourenço Guidoni' ${ }^{1}$
}

\begin{abstract}
RESUMO - Foi proposto recentemente que a solubilidade protéica in vitro com pepsina na concentração de $0,0002 \%$ é melhor que em concentrações maiores, para melhor classificar a qualidade protéica de farinhas de origem animal (FOA). Entretanto, nessa concentração, desconhece-se qual é o intervalo que melhor exprime a qualidade por meio da solubilidade protéica das FOA. Este trabalho foi conduzido com o objetivo de identificar os valores da solubilidade protéica de farinhas de subprodutos do abate de aves (FSA), utilizadas como modelo experimental. As fontes protéicas foram duas FSA e caseína (considerada padrão com 100\% de solubilidade protéica). Todas as farinhas foram autoclavadas a $120^{\circ} \mathrm{C}$, durante $0,10,20,40$ e 80 minutos. As concentrações utilizadas da pepsina em solução de $\mathrm{HCl} 0,0744 \mathrm{~N}$ foram de 0,0002 e $0,02 \%$. O delineamento experimental foi o de blocos casualizados em esquema fatorial 3 (fontes) x 5 (temperaturas) x 2 (concentrações), com quatro repetições para a enzima na concentração de $0,0002 \%$ e duas repetições para a concentração de $0,02 \%$. Foram determinados os valores de solubilidade protéica in vitro em solução ácido/pepsina e energia metabolizável in vivo das FSA. Os resultados indicaram que, na concentração de pepsina de $0,0002 \%$, os valores de boa qualidade das FSA estão acima de 55\%. Da mesma forma, solubilidades próximas a $84 \%$ podem ser consideradas boas, mas decaem em solubilidade e são consideradas ruins se tiverem em torno de $67 \%$ de solubilidade protéica em pepsina a $0,02 \%$.
\end{abstract}

Palavras-chave: metodologia, digestibilidade, ingredientes proteicos, subprodutos de origem animal

\section{Determination of Solubility of Poultry By-product with Pepsin in Low Concentration}

\begin{abstract}
It was recently proposed that the in vitro protein solubility is better to classify animal by-product meals (ABP) using pepsin concentration of $.0002 \%$ than with higher concentrations. However on this concentration no reference value exists to express ABP quality based on protein solubility. The objective of this study was to obtain protein solubility values for poultry byproduct meals (PBP), as model to ABP. Two PBP and casein (considered 100\% soluble protein) were used as protein sources. All meals were autoclaved at $120^{\circ} \mathrm{C}$, during $0,10,20,40$ and 80 minutes. Concentrations of pepsin on acid $\mathrm{HCl} 0,0744 \mathrm{~N}$ were 0.0002 and $0.02 \%$. The experiment was carried out according to a completely randomized design with factorial scheme 3 (sources) x 5 (temperatures) x 2 (concentrations), with four replications for enzyme concentration of $0.0002 \%$ and two replications for enzyme at $0.02 \%$. It were determined the in vitro protein solubility values on acid/pepsin solution and the in vivo metabolizable energy of PBP meals. The results indicated that on pepsin concentration of $0.0002 \%$, the values of good quality PBP are over $55 \%$. In the same way, solubility close to $84 \%$ could be considered good quality source, but decreasing solubility are considered bad quality with $67 \%$ on pepsin at concentration of $0.02 \%$.
\end{abstract}

Key Words: methodology, digestibility, protein ingredients, animal by-products

\section{Introdução}

Muitos laboratórios que executam o método de determinação da solubilidade protéica em pepsina baseiam-se na recomendação da Association of Official Analytical Chemists (AOAC, 1995), a qual indica que o teste deve ser feito com solução de pepsina a 0,2\% e uma atividade de 1:10000. Os estudos de Johnston \& Coon (1979), recentemente confirmado por Parsons et al. (1997) e Bellaver et al. (2000), mostram que existem diferenças em solubilidade da proteína bruta $(\mathrm{PB})(\mathrm{N} \times 6,25)$, quando digeridas em pepsina nas concentrações de 0,$2 ; 0,02$; 0,002 ou $0,0002 \%$. Isso ocorre porque, à medida que diminui a concentração da pepsina, há menor solubilidade do nitrogênio total. Entretanto, o intervalo (diferença) entre o menor e o maior valor de um conjunto de amostras aumenta à medida que diminui a concentração de pepsina (Tabela 1). Portanto, embora ocorra diminuição de nitrogênio solúvel com menor concentração de pepsina, há maior possibilidade de identificar farinhas de origem animal (FOA) de boa e

\footnotetext{
${ }^{1}$ Pesquisador da Embrapa Suínos e Aves, CEP: 89700-000, Concórdia SC. Endereço para correspondência eletrônica: bellaver@cnpsa.embrapa.br

2 Bolsista do CNPq.
} 
má qualidade. Foi proposto por Bellaver et al. (2000) que a solubilidade protéica in vitro com pepsina na concentração de 0,0002\% é melhor que, em concentrações maiores, para melhor classificar a qualidade protéica. Embora seja desejável utilizar concentração baixa de pepsina, desconhece-se qual é o intervalo que poderia exprimir melhor a solubilidade protéica desejável das FOA.

Este trabalho foi conduzido com o objetivo de identificar os valores que melhor exprimem a solubilidade protéica de farinhas de subprodutos do abate de aves (FSA), utilizadas como modelo experimental.

\section{Material e Métodos}

O experimento foi realizado no Laboratório de Análises Físico-químicas da Embrapa Suínos e Aves, em Concórdia SC. Foram executadas duas fases experimentais, sendo a primeira para determinar os valores de solubilidade protéica in vitro e a segunda, com valores in vivo obtidos para energia metabolizável (EM) dos ingredientes testados, de acordo com a metodologia de Hill \& Anderson (1958) e mais recentemente descrita por Albino (1991). A solubilidade protéica in vitro, em solução ácido/ pepsina, determina a fração solúvel das proteínas usadas no experimento, conforme método proposto por Bellaver et al. (2000). As fontes protéicas corresponderam a duas FSA e caseína (considerada padrão com $100 \%$ de solubilidade protéica), cuja as composições se encontram na Tabela 2. Todas as farinhas foram termicamente processadas em autoclave a $120^{\circ} \mathrm{C}$, durante $0,10,20,40$ e 80 minutos. As concentrações utilizadas da pepsina em solução de $\mathrm{HCl} 0,0744 \mathrm{~N}$ foram de 0,0002 e $0,02 \%$, para as fontes protéicas.

Considerando esses fatores, o delineamento experimental foi o de blocos ao acaso em esquema fatorial incompleto $3 \times 5 \times 2$ (três fontes protéicas $\mathrm{x}$ cinco níveis de processamento térmico $\mathrm{x}$ dois níveis de concentração da enzima pepsina). Foram feitas quatro repetições quando a concentração da enzima foi de $0,0002 \%$ e duas repetições para a concentração de $0,02 \%$. Após o processamento térmico, a umidade

\begin{tabular}{|c|c|c|c|}
\hline Table 1 - & $\begin{array}{l}\text { cts of pepsin concen } \\
\text { Is (MBM) }\end{array}$ & crude protein solubility & $N \times 6.25)$ of $n$ \\
\hline \multirow[t]{3}{*}{$\begin{array}{l}\text { Pepsina, \% } \\
\text { Pepsin, \% }\end{array}$} & \multicolumn{3}{|c|}{$\begin{array}{c}\text { Solubilidade da proteína bruta }(\%) \\
\text { Crude protein solubility }(\%)\end{array}$} \\
\hline & FCO com baixa PB & FCO com alta $\mathrm{PB}$ & Diferença entre as FCO \\
\hline & $M B M$ with low $C P$ & $M B M$ with high $C P$ & Difference between MBM \\
\hline 0,0002 & 33,7616 & 78,6777 & 44,92 \\
\hline 0,002 & 65,2901 & 87,0494 & 21,76 \\
\hline 0,02 & 90,9477 & 91,9651 & 1,02 \\
\hline 0,2 & 90,9562 & 91,9653 & 1,01 \\
\hline
\end{tabular}

${ }^{1}$ Fonte (Source): Bellaver et al. (2000).

Tabela 2 - Composição das fontes protéicas (caseína e subproduto do abate de aves) Table 2 - Composition of protein sources (casein and poultry by-products)

\begin{tabular}{lccccc}
\hline $\begin{array}{l}\text { Fontes } \\
\text { Sources }\end{array}$ & $\begin{array}{c}\text { Matéria seca }(\%) \\
\text { Dry matter }\end{array}$ & $\begin{array}{c}\text { Proteína bruta }(\%) \\
\text { Crude protein }\end{array}$ & $\begin{array}{c}\text { Cinzas }(\%) \\
\text { Ash }\end{array}$ & $\begin{array}{c}\text { Lisina digestível }(\%)^{1} \\
\text { Digestible lysine }\end{array}$ & $\begin{array}{c}\text { EM kcal/kg } \\
\text { ME }\end{array}$ \\
\hline $\begin{array}{l}\text { Caseína } \\
\text { Casein }\end{array}$ & 98,00 & 80,00 & - & - & - \\
FSA1 & 93,85 & 53,01 & 17,11 & 80 & 3601 \\
PBP1 & 92,36 & 51,73 & 16,46 & 89 & 4137 \\
FSA2 & & & & &
\end{tabular}

${ }_{1}^{1}$ Determinado segundo Sibbald (1979), adaptado por Parsons (1985).

1 Determined according to Sibbald (1979), adapted by Parsons (1985). 
das fontes protéicas foi estabilizada em estufa a $45^{\circ} \mathrm{C}$, por 16 horas, e analisadas quanto à solubilidade protéica, de acordo com Bellaver et al. (2000).

\section{Resultados e Discussão}

Os resultados alcançados encontram-se na Tabelas 3 e 4 e na Figura 1. As fontes protéicas trabalhadas apresentaram concentrações de proteína bruta (PB), digestibilidade da lisina e energia metabolizável conforme dados da Tabela 1. Na Figura 1, observa-se que a caseína, como esperado, foi altamente digestível (100\%) na concentração de pepsina de $0,0002 \%$, servindo de referência de fonte completamente solúvel na pepsina nessa concentração, não havendo efeitos associados ao tempo e à temperatura elevada de processamento. As FSA digeridas em pepsina $0,0002 \%$ apresentaram maior variabilidade nas amostras testadas, o que já era esperado (Bellaver et al., 2000). Os valores dos interceptos foram, respectivamente, de 54,90 e $60,84 \%$ de solubilidade protéica em pepsina e $\mathrm{HCl}$ (SOLPEP), para as FSA 2 e FSA 1. Aumentando a concentração da enzima para $0,02 \%$, o intercepto da solubilidade protéica no tempo zero de processamento térmico foi

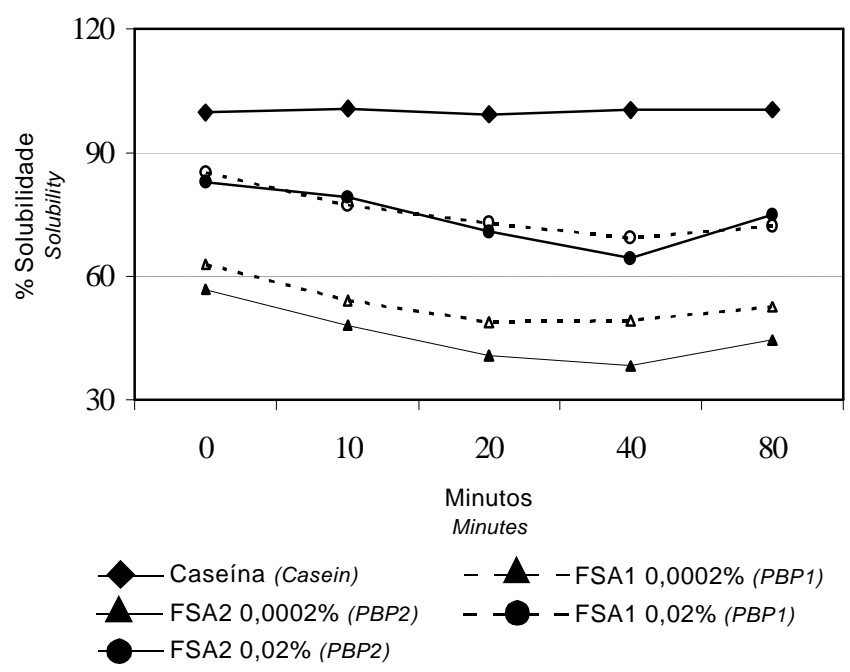

Figura 1 - Efeito do tempo de autoclavagem $\left(120^{\circ} \mathrm{C}\right)$ sobre a solubilidade da PB.

Figure 1 - Effect of autoclaving time $\left(120^{\circ} \mathrm{C}\right)$ on crude protein solubility.

R. Bras. Zootec., v.33, n.5, p.1167-1171, 2004 semelhante entre as duas farinhas (84,2\%). Quando a solubilidade foi avaliada no ponto mínimo estimado, os valores situaram-se entre 38,62 e $45,29 \%$ para pepsina $0,0002 \%$ e entre 64,83 e $67,40 \%$ para pepsina $0,02 \%$.

Uma vez que as equações estimadas (Tabela 4) guardam coerência com trabalhos anteriores (Bellaver et al., 2000; Parsons et al., 1997) e as estimativas de seus parâmetros são todas significativas, com coeficientes de correlação também significativos; pode-se indicar que solubilidades ideais com concentrações de pepsina de $0,0002 \%$ estão acima de $55 \%$, sendo indicativas de farinhas de boa qualidade nutricional. Abaixo desse valor podem estar associadas a danos de processamento ou de composição química. Nessa concentração enzimática, valores inferiores a $45 \%$ de SOLPEP podem ser indicativo de má qualidade das FSA. Da mesma forma, solubilidades próximas a $84 \%$ podem ser consideradas boas, mas decaem em solubilidade e são consideradas ruins se tiverem em torno de $67 \%$ de solubilidade protéica em pepsina $0,02 \%$.

Assim, as indicações do Compêndio Brasileiro de Alimentação Animal (1998) precisam ser ajustadas para exprimir os valores referência para testes de solubilidade em pepsina $\mathrm{HCl}$. No referido Compêndio, as farinhas de penas e vísceras e farinha de vísceras devem apresentar os mínimos de 40 e $60 \%$ de SOLPEP a $0,02 \%$, respectivamente. Nesse trabalho, as solubilidades consideradas boas para a concentração de $0,02 \%$ deveriam ser em torno de $84 \%$ e, quando os valores reduzirem, há piora de qualidade. Extrapolando para o ponto de mínima solubilidade (próximo a 67\%), a solubilidade desejável para FSA com a metodologia que utiliza pepsina a $0,02 \%$, considerando arredondamento para facilidade de uso, não deveria ser inferior a $70 \%$. Entretanto, reafirma-se que a SOLPEP representa melhor a qualidade das farinhas, quando executada com concentração de $0,0002 \%$ de pepsina.

Neste trabalho, são apresentados os resultados para comparar os métodos de digestão em pepsina e $\mathrm{HCl}$ e como os valores obtidos devem ser interpretados. É possível que os resultados possam ser melhorados com maior variabilidade de fontes protéicas de origem animal. No entanto, as estimativas obtidas são significativas e consistentes, como se observa na Tabela 4. Portanto, o resultado tem aplicabilidade imediata na indústria de rações e de processamento de farinhas animais. 
Tabela 3 - Valores médios da solubilidade protéica em pepsina Table 3 - Average values of protein solubility on pepsin

\begin{tabular}{|c|c|c|c|c|}
\hline \multirow[t]{2}{*}{$\begin{array}{c}\text { Tratamento } \\
\text { Treatment }\end{array}$} & \multirow[t]{2}{*}{$\begin{array}{l}\text { Fonte }^{1} \\
\text { Source }\end{array}$} & \multirow[t]{2}{*}{$\begin{array}{l}\text { Tempo em minutos } \\
\text { Time in minutes }\end{array}$} & \multicolumn{2}{|c|}{$\begin{array}{c}\text { Solubilidade em pepsina } \\
\text { Pepsin solubility }\end{array}$} \\
\hline & & & $0,0002 \%$ & $0,02 \%$ \\
\hline 1 & $\begin{array}{l}\text { FSA1 } \\
P B P 1\end{array}$ & 0 & 62,873 & 85,223 \\
\hline 2 & $\begin{array}{l}\text { FSA1 } \\
P B P 1\end{array}$ & 10 & 54,275 & 77,302 \\
\hline 3 & $\begin{array}{l}\text { FSA1 } \\
P B P 1\end{array}$ & 20 & 48,845 & 72,991 \\
\hline 4 & $\begin{array}{l}\text { FSA1 } \\
P B P 1\end{array}$ & 40 & 49,308 & 69,319 \\
\hline 5 & $\begin{array}{l}\text { FSA1 } \\
P B P 1\end{array}$ & 80 & 47,752 & 72,170 \\
\hline 6 & $\begin{array}{l}\text { FSA2 } \\
P B P 2\end{array}$ & 0 & 56,759 & 82,876 \\
\hline 7 & $\begin{array}{l}\text { FSA2 } \\
P B P 2\end{array}$ & 10 & 48,164 & 79,114 \\
\hline 8 & $\begin{array}{l}\text { FSA2 } \\
P B P 2\end{array}$ & 20 & 40,798 & 70,793 \\
\hline 9 & $\begin{array}{l}\text { FSA2 } \\
P B P 2\end{array}$ & 40 & 42,201 & 64,499 \\
\hline 10 & $\begin{array}{l}\text { FSA2 } \\
P B P 2\end{array}$ & 80 & 44,472 & 74,923 \\
\hline 11 & $\begin{array}{c}\text { Caseína } \\
\text { Casein }\end{array}$ & 0 & 99,814 & , \\
\hline 12 & $\begin{array}{l}\text { Caseína } \\
\text { Casein }\end{array}$ & 10 & 100,680 & , \\
\hline 13 & $\begin{array}{l}\text { Caseína } \\
\text { Casein }\end{array}$ & 20 & 99,438 & , \\
\hline 14 & $\begin{array}{c}\text { Caseína } \\
\text { Casein }\end{array}$ & 40 & 100,382 & , \\
\hline 15 & $\begin{array}{c}\text { Caseína } \\
\text { Casein }\end{array}$ & 80 & 100,498 & , \\
\hline
\end{tabular}




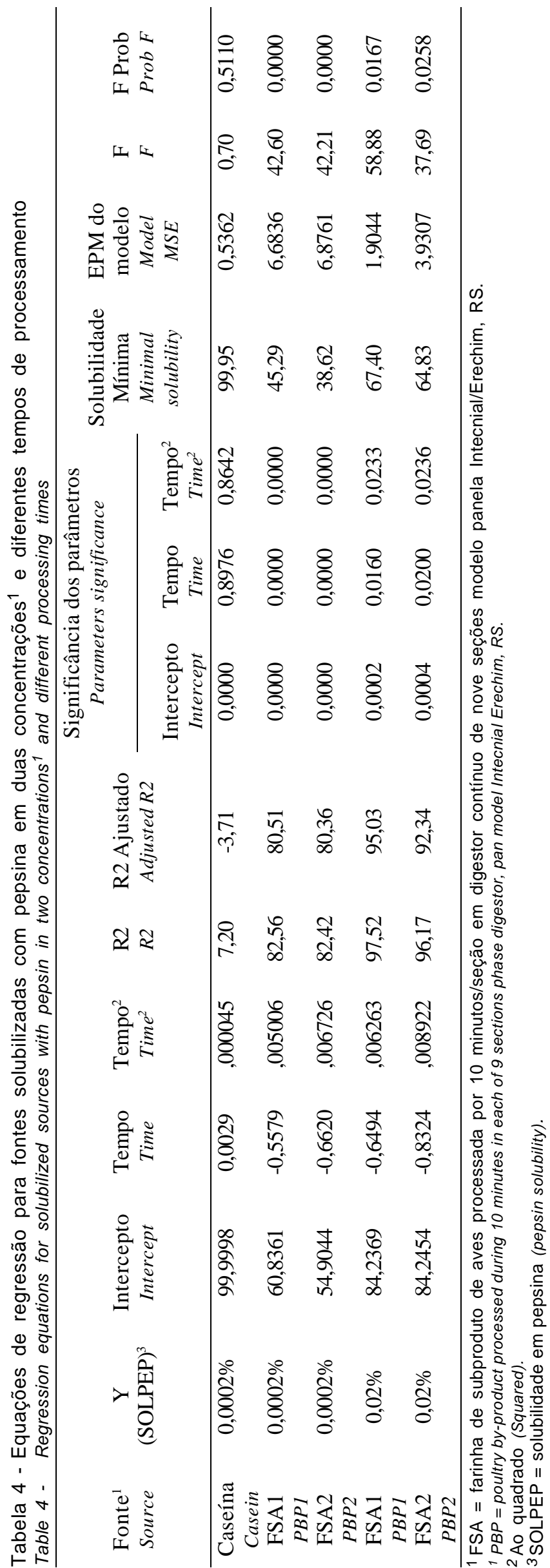

\section{Conclusões}

Os resultados permitem concluir que $55 \%$ ou mais de solubilidade protéica de farinhas de subprodutos do abate de aves, com pepsina na concentração de $0,0002 \%$, é indicativo de farinhas de subprodutos de aves de boa qualidade nutricional. Outros valores para outros ingredientes de origem animal devem ser calculados.

\section{Literatura Citada}

ALBINO, L.F.T. Avaliação nutricional de alimentos e suas aplicações na formulação de rações para frangos de corte. Viçosa, MG: Universidade Federal de Viçosa, 1991. 141p. Tese (Doutorado em Zootecnia) - Universidade Federal de Viçosa, 1991.

ASSOCIATION OF OFFICIAL ANALYTICAL CHEMISTS AOAC. Pepsin digestibility of animal protein feeds. In: CUNNIFF, P. (Ed.) Official methods of analysis of AOAC international. 16.ed. 1995. p.15-16.

BELLAVER, C.; ZANOTTO, D.L.; GUIDONI, A.L. et al. In vitro solubility of meat and bone meal protein with different pepsin concentrations. Ciência Rural, v.30, n.3, p.489-492, 2000.

COMPÊNDO BRASILEIRO DE ALIMENTAÇÃO ANIMAL. São Paulo: SINDIRAÇÕES/ANFAL; Campinas: CBNA/ SRD/MA, 1998. 371p.

HILL, F.W.; ANDERSON, D.L. Comparation of metabolizable energy and productive energy determination with growing chicks. Journal of Nutrition, v.64, p.587-603, 1958.

JOHNSTON, J.; COON, C.N. The use of varying levels of pepsin for pepsin digestion studies with animal proteins. Poultry Science, v.58, p.1271-1273, 1979.

PARSONS, C.M.; CASTANON, F.; HAN, Y. Protein and amino acid quality of meat and bone meal. Poultry Science, v.76, p. 361-368, 1997.

PARSONS, C.M. Amino acid availability in feedstuffs for poultry and swine. In: BAKER, D.H.; PARSONS, C.M. (Eds.) Recent advances in amino acid nutrition. Tokyo: Ajinomoto Co., 1985. p.35-47.

SIBBALD, I.R. A bioassay for available amino acids and true metabolizable energy in feedingstuffs. Poultry Science, v.58, p.668-673, 1979.

Recebido em: $14 / 03 / 03$

Aceito em: $05 / 12 / 03$

R. Bras. Zootec., v.33, n.5, p.1167-1171, 2004 